\title{
PROPOSIÇÕES PARA O ESTUdO DO ESPORTE CONTEMPORÂNEO
}

\author{
Marcelo Weishaupt Proni \\ Universidade Estadual de Campinas / Brasil \\ mwproni@,eco.unicamp.br
}

\section{Resumo}

Ao longo do século XX, o mundo esportivo passou por profundas mudanças e se tornou mais complexo e mais heterogêneo. Autores de diferentes matrizes teóricas têm estudado o esporte contemporâneo e proposto caminhos coerentes para a sua interpretação. O objetivo deste artigo é apontar algumas ideias que permitam combinar estudos de caráter histórico e sociológico sobre o esporte, assim como discutir brevemente algumas teses sobre a configuração do mundo esportivo nas sociedades contemporâneas. Em especial, procura-se contrapor o argumento de que há uma ruptura no desenvolvimento do esporte produzida pela pós-modernidade e destacar o maior dinamismo do esporte-espetáculo.

Palavras-chave: história do esporte; sociologia do esporte; teoria do esporte.

\section{Propuestas PARA EL ESTUdio DEL DEPORTE CONTEMPORÂNEO}

\section{Resumen}

Durante los últimos cien años, el mundo del deporte ha experimentado profundos cambios y se hizo más complejo y heterogéneo. Los autores de diferentes marcos teóricos han estudiado el deporte contemporáneo y propuesto coherentes métodos para su interpretación. El objetivo de este trabajo es poner de relieve algunas ideas que combinan estudios históricos y sociológicos sobre el deporte, así como discutir brevemente algunas teorías acerca de la configuración del mundo del deporte en las sociedades contemporáneas. En particular, se busca contrarrestar el argumento de que hay una ruptura en el desarrollo del deporte producida por la post-modernidad, y hacer hincapié en el gran dinamismo del deporte espectáculo.

Palabras-clave: historia del deporte; sociología del deporte; teoría del deporte.

PROPOSALS FOR THE STUDY OF CONTEMPORARY SPORT
Abstract
Throughout the twentieth century, the sports world has undergone profound changes and became
more complex and heterogeneous. Authors from different theoretical framework have studied the
contemporary sports, and they have indicated coherent ways for its interpretations. The aim of this
paper is to propose some ideas that connect historical and sociological studies about the sport, as well
as briefly discuss some thesis about the configuration of the sports world in contemporary societies. In
particular, it seeks to counter the argument that there is a break in the sports development produced by
post-modernity and highlight the dynamism of sport spectacle.

Key-words: history of sport; sociology of sport; theory of sport. 


\section{Introdução}

O que se pode chamar atualmente de "mundo esportivo" - isto é, o conjunto de práticas, instituições e relações sociais existentes em razão do esporte - se constituiu historicamente a partir do século XIX, principalmente na Inglaterra, foi se expandindo aos poucos para uma gama cada vez maior de nações e se metamorfoseou à medida que a sociedade moderna se transformava (Proni, 1998). Desde então, foram se multiplicando as modalidades esportivas, cresceu o número de praticantes, surgiram torneios nacionais e internacionais, criou-se uma separação entre amadores e profissionais, formaram-se públicos apaixonados pelo espetáculo esportivo, ampliou-se o seu espaço nos meios de comunicação, foram inventadas tradições esportivas, foram desenvolvidos sofisticados métodos de treinamento e se tornou freqüente a influência política e econômica na organização e promoção do esporte.

O estudo específico do lugar e do papel do esporte na sociedade contemporânea avançou bastante nos últimos cinquenta anos. Os primeiros ensaios procurando delimitar o esporte como campo privilegiado de análise e utilizando uma matriz teórica para embasar as proposições sobre a estrutura e a dinâmica das relações ali observadas começaram a ser divulgados na década de 1960 . Surgiram então muitas abordagens bem fundamentadas e instigantes a respeito da funcionalidade do esporte na reprodução da ordem social, destacando as motivações e interesses dos praticantes ou a finalidade e as repercussões das instituições esportivas. Destacam-se, entre os pioneiros, autores com perspectivas bastante distintas, como Bero Rigauer, Jean-Marie Brohm, Allen Guttmann, Pierre Bourdieu, José Maria Cagigal, Norbert Elias e Eric Dunning (Proni; Lucena, 2003; Vaz, 2007).

Também se multiplicaram estudos sobre a gênese e evolução do esporte, com a preocupação de estabelecer uma periodização e demonstrar que, ao longo do tempo, as relações sociais no mundo esportivo foram se tornando mais densas e complexas, acompanhando o curso das transformações econômicas, políticas, sociais e tecnológicas (Mandell, 1984). Em consequência desse adensamento, as questões que se colocam para o esporte, atualmente, são em maior número e envolvem maior complexidade, se comparadas com as que podiam ser formuladas há cem anos. Houve uma ampliação do rol de questões e interesses que se estabelece em torno das práticas esportivas, o que levou muitos pesquisadores - tais como Lüschen e Weis (1979), Pociello (1984), McPherson, Curtis e Loy (1989) e Garcia Ferrando (1990) - a entenderem o esporte como um fenômeno em expansão que exige a incursão em novos e inquietantes temas. Conforme explica Ademir Gebara (1995: 126):

Massificação dos esportes, socialização da mulher, compor critérios para definir status na crescente burguesia européia, soldar laços nacionais, foram questões centrais colocadas quando da constituição do esporte moderno, na passagem do século XIX para o XX. Americanização, globalização, imperialismo cultural, modernidade e espetacularização, são questões centrais colocadas no sentido de compreender a 
dimensão e o significado assumido pelo esporte nos dias de hoje. Estamos falando de continuidades e rupturas de um fenômeno, talvez único, que nos últimos cem anos tem se expandido constante e, talvez, irremediavelmente.

Além disso, a discussão em torno de questões colocadas pela expansão do mundo esportivo tende a considerar, também, que a evolução recente do esporte manifestou as tensões da sociedade pósindustrial, incorporou muitos avanços no campo científico e trouxe novas possibilidades de interação social. Mas é necessário esclarecer que o surgimento de novos elementos não acarretou uma descontinuidade radical nas formas e funções tradicionais do esporte (Holt, 1989).

Note-se que os estudos mais conhecidos tomam o esporte na Europa e nos Estados Unidos como referência central. Todavia é importante mencionar que desde o final da década de 1990 foram exploradas várias trilhas de pesquisa no terreno do esporte na América Latina (Villena, 2003), possibilitando falar em surgimento de uma identidade latino-americana para estudos nesse campo (Cornejo; Marchi Jr., 2008).

Neste artigo, não seria possível abordar toda a vasta e rica produção acadêmica que está disponível atualmente para guiar as pesquisas no campo do esporte. Pretende-se apenas apontar algumas ideias que permitem conciliar os estudos de caráter histórico e sociológico sobre o esporte, assim como discutir brevemente algumas teses sobre a configuração e a dinâmica do mundo esportivo nas sociedades contemporâneas.

\section{Toda teoria geral do esporte tem uma abrangência circunscrita}

$\mathrm{Na}$ maioria dos cursos de Educação Física ainda predomina uma abordagem que, para evidenciar a diversidade de práticas e motivações encontradas no mundo esportivo, procura apresentar tipologias que classificam as modalidades segundo critérios "técnicos" ou "utilitários". Por exemplo, as modalidades esportivas podem ser classificadas em pelo menos nove categorias: 1) esportes olímpicos (atletismo, natação); 2) esportes tradicionais (futebol, beisebol); 3) esportes de risco ou desafio (skate, ralis); 4) esportes na natureza (corridas de orientação, surfe); 5) esportes marciais (judô, karatê); 6) esportes intelectivos (xadrez, bilhar); 7) esportes de identidade cultural (capoeira, críquete); 8) esportes de conteúdo estético (dança esportiva, patinação artística); e 9) esportes derivados de outros (futevôlei, vôlei de praia).

Contudo, tipologias baseadas em tais critérios são limitadas quando se trata de uma análise histórica e/ou sociológica. Não apenas por estarem sujeitas a constantes revisões, mas porque acabam perdendo de vista o foco dos estudos explicativos sobre o esporte, a saber: seu significado social múltiplo e suas relações com outras esferas de sociabilidade. Não se pode atribuir uma função social exclusiva a cada modalidade esportiva. Uma mesma modalidade pode ser desfrutada como prática 
recreativa, ser utilizada com uma finalidade específica (manutenção da saúde, dar vazão para a agressividade, fortalecimento do patriotismo etc.), ser apresentada como espetáculo de massa e assim por diante.

Em adição, quando se trata de entender a constituição e transfiguração do mundo esportivo, é evidente que não se pretende oferecer uma narrativa que abarque a história completa do esporte no mundo, ou mesmo num conjunto específico de países, uma vez que isto exigiria colecionar uma infinidade de estudos de caso.

Da mesma forma, ao selecionar as referências teóricas que ajudam a entender a dinâmica do esporte contemporâneo, não é preciso escolher uma "teoria geral" que seja válida para toda e qualquer experiência concreta. É preciso, acima de tudo: (i) compreender que o esporte contemporâneo não é um fenômeno monolítico; (ii) saber que, por envolver uma multiplicidade de práticas e de significados, permite (ou exige) uma variedade de leituras e interpretações; e (iii) circunscrever a contribuição de diferentes abordagens para poder valorizá-las.

Entre os autores brasileiros que escreveram sobre o esporte de uma perspectiva sociológica, é possível encontrar abordagens bastante distintas. Como ilustração, podem ser citados aqui quatro livros que adotam diferentes paradigmas. Teoria geral do desporto, de Manoel Tubino, procura destacar as diferentes formas de manifestação e nos variados significados sociais do esporte, tomando como ponto de partida os escritos de Cagigal, que estabelece uma separação entre o esporte escolar, o esporteespetáculo e o esporte para todos. O que é sociologia do esporte, de Ronaldo Helal, esclarece como o esporte se situa no universo do jogo e procura enfatizar o processo de racionalização das práticas competitivas, tomando como referência central a abordagem de Guttmann. Sociologia crítica do esporte, de Valter Bracht, baseia-se na sociologia crítica da Escola de Frankfurt para tecer sua leitura a respeito da influência da mercantilização sobre a organização de práticas esportivas e para colocar em evidência os desvios em relação ao ideal olímpico. E O esporte na cidade, de Ricardo Lucena, estudo que fica na fronteira entre a história e a sociologia, procurando explorar as categorias de análise sugeridas na obra de Elias para compreender a ação civilizadora do esporte no Rio de Janeiro e sua influência sobre a construção de identidades culturais.

Movimento semelhante pode ser encontrado em outros países latino-americanos. Ou seja, também na Argentina, no México, no Chile e em outras nações do continente foram realizados estudos sociológicos com abordagens muito distintas sobre o esporte, indicando uma diversidade de temas e uma multiplicidade de enfoques teóricos.

Não há problema em examinar o mundo esportivo a partir de uma única abordagem, mas é preciso deixar claro qual o propósito do estudo. Por exemplo, numa análise inspirada em Bourdieu que entende o campo esportivo como um conjunto bastante heterogêneo de competições corporais que 
reúnem uma infinidade de atores sociais -, pode-se priorizar a diferenciação social que se verifica na interação entre os agentes e se manifesta na segmentação das práticas em "mercados" associados a uma série de "consumos culturais"; e pode-se propor que certas escolhas e hábitos neste campo se definem a partir de demandas sociais por atividades de lazer, assim como da diversificação na oferta de entretenimento. Esta abordagem pode dar sustentação a estudos temáticos que procurem examinar como estão estruturadas a oferta e a demanda por modalidades esportivas, buscando explicitar as diferentes forças que interferem na mudança estrutural de um campo esportivo específico (Marchi Jr 2004).

Mas, a teoria do campo esportivo de Bourdieu não pode ser tomada como uma teoria capaz de dar respostas satisfatórias a quaisquer perguntas sobre temas relativos ao mundo esportivo, uma vez que a adoção de uma abordagem teórica condiciona o tipo de perguntas a serem feitas. O mesmo pode ser dito em relação à teoria do processo civilizador de Elias, à teoria da modernização de Guttmann, à teoria da mercantilização de Rigauer e em relação a outras referências teóricas relevantes.

\section{O esporte reproduz as características e tensões da modernidade}

É conveniente esclarecer que o motivo para diferentes autores divergirem na compreensão dos processos sociais que deram origem ao esporte moderno, ou que melhor explicam as funções do esporte contemporâneo, não se restringe ao fato de se apoiarem em distintos modelos de análise. Existem, além disso, diferenças de entendimento do que constitui a "modernidade". Ou seja, em virtude de cada abordagem privilegiar um ou outro aspecto, essa ou aquela faceta das sociedades modernas, autores como Guttmann, Elias e Bourdieu acabam formulando explicações parciais, ou seja, interpretações que destacam certos processos, mas não poderiam apreender o conjunto das transformações que resultaram em realidades sociais cada vez mais complexas.

Explicando melhor: se Guttmann fala de racionalização e burocratização, se Elias destaca o controle da violência e a satisfação de necessidades emocionais dos indivíduos, se Bourdieu enfatiza os determinantes da oferta e da demanda de práticas culturais, pode-se dizer que cada um aponta uma vertente importante do processo geral de formação das sociedades modernas, que ilumina certas ações e aspirações de indivíduos concretos. E, em decorrência, cada um aponta uma vertente do processo de constituição e constante mudança do mundo esportivo.

Há pesquisadores que procuram combinar essas diferentes vertentes, justamente por optar por um enfoque que não se prenda a um modelo único de interpretação. De qualquer modo, poucos discutem as contradições da modernidade, tão importantes para entender, por exemplo, o confronto entre amadorismo e profissionalismo, ou para avaliar os impulsos e resistências aos processos de mercantilização e espetacularização das práticas esportivas. 
Uma das melhores explicações sobre as tensões da modernidade foi formulada por João Manuel Cardoso de Mello e Fernando Novais. Para entender a sociabilidade moderna - os valores e práticas sociais que fundamentam e orientam a vida das pessoas na modernidade - é preciso um esforço duplo, procurando apreender a dinâmica das relações sociais diante da progressiva constituição do capitalismo e, ao mesmo tempo, investigar a própria origem da identidade moderna, na qual se assentam todas as relações sociais da modernidade. Por isso, eles concebem a modernidade como a confluência de dois campos de força em permanente tensão: de um lado, o utilitarismo e os valores mercantis; de outro, o humanismo e as ideias do iluminismo. A explicação de Cardoso de Mello e Novais (2009: 44-5) é a seguinte:

Os valores capitalistas - a idéia de liberdade entendida como escolha desembaraçada da tradição e de obstáculos externos à manifestação da vontade, isto é, a concepção negativa de liberdade; o postulado de que cada indivíduo é capaz de ação racional, de calcular vantagens e desvantagens ajustadas à realização de seus interesses materiais ou de seus desejos, isto é, o hommo economicus utilitário; o pressuposto de que a concorrência entre indivíduos formalmente livres e iguais acaba premiando cada um segundo seus méritos e dons; o princípio de que o jogo dos interesses individuais leva à harmonia social e ao progresso sem limites, isto é, de que o mercado é o estruturador da sociedade e o motor da história - podem se impor graças à sua funcionalidade para o desenvolvimento do sistema econômico. Mas não devem ser confundidos com o conjunto dos valores modernos. Como se sabe, os valores modernos têm outras fontes morais que emergem, de um lado, da Reforma Protestante e da Igreja Católica, e, de outro, do racionalismo ilustrado, especialmente nas suas vertentes radicais. Pensamos, sobretudo, de um lado, no valor do trabalho como fim em si mesmo, do respeito pelo próprio corpo, da família fundada no companheirismo e na educação dos filhos, da moral sexual rigorista; e, de outro, no valor da autonomia, dos direitos do cidadão, da igualdade real, da educação republicana, do desenvolvimento espiritual, da criatividade e da autenticidade. Historicamente, a modernidade resulta e avança por meio da tensão permanente entre o conjunto de valores mercantis, utilitários, propriamente capitalistas, e o outro conjunto de valores, fundamentados seja religiosa, seja secularmente. Mais ainda: são os valores modernos não mercantis, não capitalistas que, corporificados em instituições (a democracia de massas, a escola republicana, as igrejas, a família cristã etc.), põem freios ao funcionamento desregulado e socialmente destrutivo do capitalismo.

O humanismo, de inspiração religiosa, valorizou o trabalho, a solidariedade cristã e o cuidado do corpo (templo da alma). O iluminismo, de cunho filosófico e político, defendeu a preponderância da razão cartesiana, a secularização das instituições sociais, a capacidade criativa do homem e seu livrearbítrio. O mercantilismo e o utilitarismo, fundados nas relações de troca e na praticidade do mundo dos negócios, enfatizaram o cálculo, a busca da eficiência, a organização burocrática e a compartimentalização do tempo. Essas três correntes provavelmente tiveram influências distintas (mas que se misturam) sobre a esportivização de jogos e passatempos e sobre a constituição do mundo esportivo - processo que, como se sabe, ocorreu precocemente na Inglaterra. 
Portanto, para compreender mais amplamente as diferentes forças socioculturais responsáveis pela constituição de modalidades esportivas e pela transfiguração e diversificação dessas práticas, é necessário combinar as mudanças nas condições materiais de vida (induzidas pela industrialização, pela urbanização, pelo progresso tecnológico e pela ação do Estado) com as mudanças na mentalidade e nos hábitos dos diferentes grupos sociais (decorrentes do avanço da racionalidade científica, da organização burocrática, da civilização dos costumes, do espírito empreendedor e da mercantilização da cultura). E é necessário levar em conta que no mundo moderno modificou-se a estrutura da personalidade dos membros que compõem a sociedade, o que alterou suas necessidades psicológicas básicas. Mas não se trata de juntar todos esses ingredientes num caldeirão. Uma compreensão ampla, coerente e objetiva exige investigar como eles se combinam em cada período histórico, analisar como o processo de legitimação se desenrola com peculiaridades próprias em cada nação, assim como perguntar por que em cada cultura predomina este ou aquele conjunto de valores.

\section{O termo "esporte pós-moderno" pode conduzir a um entendimento equivocado}

As questões que poderiam ser examinadas numa investigação com esta ampla perspectiva são inúmeras. Neste artigo, é oportuno discutir um tema em particular: a superação dos elementos característicos da sociedade moderna e a possível emergência de um esporte "pós-moderno". Na visão de Douglas Kellner, por exemplo, a progressiva mercantilização do mundo esportivo rompeu a relativa autonomia que este guardava em relação à economia (de modo análogo, o mesmo se aplica à política), estabelecendo uma separação clara entre o "esporte moderno" (produto das sociedades urbanoindustriais do século XIX) e o que ele chama de "esporte pós-industrial" (produto das sociedades informatizadas da era atual). Nas suas palavras (Kellner, 1996: 459):

O esporte moderno [...] foi organizado em torno de princípios da divisão social do trabalho e do profissionalismo, celebrando valores modernos de competição e de vitória. O esporte moderno reproduziu a estrutura do local de trabalho, onde tanto a iniciativa individual como o trabalho de equipe eram necessários, e o esporte celebrou ao mesmo tempo ambos os valores concorrentes. Não obstante, o esporte era parte de um reino autônomo, com sua própria ética profissional, papéis cuidadosamente regulamentados e estrutura corporativa altamente organizada. O esporte pósindustrial, em contraste, transverte o esporte em espetáculo da mídia, desmorona as fronteiras entre atividade profissional e comercialização, e afirma a mercadorização de todos os aspectos da vida na sociedade de consumo e de comunicação de massa.

Esse modo de enfocar a transfiguração do mundo esportivo ao longo do século XX é partilhado por vários estudiosos. Porém, é uma visão muito esquemática, destinada a realçar uma profunda ruptura na vida cultural das nações desenvolvidas. Sua validade depende do que se entende 
por "reino autônomo", "modernidade" e "sociedade pós-industrial", assim como do modo como é entendida a dinâmica cultural.

Sem dúvida, o mundo esportivo do século XIX tendia a reproduzir os valores burgueses de sua época e a mentalidade dos atores sociais que dele se apropriaram, mas isto não significa que a modernização representou uma completa superação de aspectos tradicionais, fossem eles aristocráticos ou populares (Holt, 1989). Formou-se um mundo híbrido e diversificado. Em contraposição aos esportes profissionais e ao universo das apostas, o esporte das public school e dos novos clubs não se deixou permear por uma lógica mercantil. Mesmo o futebol, quando se organizou como espetáculo, manteve uma gestão amadora e não se converteu em negócio (muito menos em atividade empresarial). Embora a maioria dos esportes não fizesse parte, ainda, do jogo de interesses diplomáticos e de um discurso político nacionalista, já estavam claras as influências das culturas nacionais na preferência por certas práticas e na maneira como cada povo entendia o que era uma "vida esportiva", na Europa e nos EUA.

Pode-se dizer que os princípios que passaram a estruturar as práticas esportivas de alto rendimento, em especial na segunda metade do século XX, responderam a uma nova conjunção de fatores sociais, econômicos e políticos, permitindo estabelecer um divisor de águas entre o esporte burguês da época de constituição de sociedades urbano-industriais e o esporte-espetáculo da era da globalização. Porém, uma visão que advoga a transformação definitiva do esporte numa atividade "pósmoderna" e, aparentemente, ignora as várias funções e representações do esporte na vida das pessoas, pode fazer acreditar que o estudo do esporte pode se limitar à investigação de suas configurações mais visíveis (tais como o sucesso do fenômeno Michael Jordan - NBA - Nike).

Considerando válido o modo como Cardoso de Mello e Novais definem a modernidade, não há nenhum vetor radicalmente novo nessa "pós-modernidade" do ponto de vista das grandes forças que forjaram a sociedade e o homem contemporâneos. Há, isto sim, um desequilíbrio crescente, que pende em favor das forças do utilitarismo e do mercantilismo. Ou seja, aqueles princípios que compensavam a lógica alienante própria do capitalismo são cada vez mais impotentes e a cultura de massa é cada vez mais predominante. O que a tal sociedade "pós-industrial" faz é levar ao extremo os paradoxos da modernidade, permitindo que o individualismo exacerbado conduza ao "esmagamento do eu", como diria Christopher Lasch (1986).

Uma interpretação convergente é expressa por Eric Hobsbawm (1995: 25). Para ele, a sociedade formada por um "[...] conjunto de indivíduos egocentrados [...]”, sem maiores vínculos entre si, “[...] em busca apenas da própria satisfação (o lucro, o prazer ou seja lá o que for) [...]”, esteve presente nas interpretações do capitalismo desde o século XIX. Mas, durante muito tempo, a sociedade moderna havia podido (ou aprendido a) conter o ímpeto dessa lógica do "individualismo radical" e preservar os 
laços de sociabilidade que herdara da velha sociedade, "adaptando seletivamente a herança do passado para uso próprio". Porque, segundo ele, o modo mais "eficaz" de erigir uma economia industrial fundada na empresa privada tinha sido aquele que incorpora aspirações e motivações que não provinham da órbita econômica - como a ética protestante, a glorificação do trabalho, a noção de dever familiar. Contudo, nas últimas décadas do século XX, o capitalismo parecia ter escapado aos controles sociais e, de acordo com Hobsbawm, a sua racionalidade utilitária estava se impondo progressivamente sobre a organização das mais diferenciadas esferas de sociabilidade.

Como a sociedade contemporânea apresenta descontinuidades em relação à anterior, mas ao mesmo tempo manifesta tendências que já estavam embutidas naquela sociedade burguesa, não surpreende que o mesmo ocorra com o esporte. É fácil constatar que há muitas descontinuidades no mundo esportivo, as quais não se restringem à órbita do mercado e do espetáculo, remetendo a novas subjetividades que aparecem nos esportes radicais, nos esportes de aventura, nos esportes praticados em shopping center, nos esportes high tech. Porém, mesmo nesses casos, é preciso cuidado ao utilizar o termo "pós-moderno" e ao projetar tendências para o século XXI. Talvez seja acertado acompanhar Zygmunt Bauman (2001) e falar em "modernidade líquida" - definição que procura ressaltar as profundas mudanças de comportamento em curso nas sociedades contemporâneas e iluminar os novos dilemas que assolam os indivíduos imersos em relações sociais aparentemente menos densas e mais efêmeras -, mas é preciso ser prudente para não exagerar nas metáforas, não sepultar a rica herança e não perder de vista o conjunto híbrido e multifacetado.

$\mathrm{Na}$ verdade, o mundo esportivo não se transfigurou por completo. Se, por um lado, apareceram novas práticas, novos princípios estruturantes, novas conexões de sentido, por outro, procurou-se preservar a base sobre a qual o esporte se constituiu, antes de ser dominado pela cultura de massa. Por isso, não surpreende que existam interpretações apontando em direções opostas. O esporte pode ser visto, por exemplo, como produto da indústria cultural capitalista e como reprodutor de relações sociais alienantes e reificadoras. Em oposição, também com razão, persiste a opinião contrária: que procura resgatar no esporte os valores que lhe deram significado; que assegura ser o mundo esportivo, ainda, um refúgio para a sociabilidade pautada em princípios éticos; que realça a existência silenciosa de práticas e hábitos esportivos impermeáveis à lógica da acumulação e do consumismo.

Também nas sociedades latino-americanas o discurso da "pós-modernidade" tem produzido uma gama de leituras fragmentadas e pasteurizadas sobre o papel social do esporte, às quais se contrapõem leituras pautadas na sua importância para a construção de identidades nacionais e para a canalização de tensões sociais (Alabarces, 2003). A conclusão é simples: não se pode contestar que o esporte-espetáculo tenha se tornado uma realidade fugaz vinculada com o consumo massificado, com a globalização cultural e com a dinâmica política internacional (Ribeiro, 2007), mas não se pode esquecer 
que o mundo esportivo, na América Latina atual, continua alicerçado em atividades lúdicas que oferecem possibilidades de expressão subjetiva, de ação educativa e de construção de identidades duradouras, podendo criar relações de proximidade em lugar de intensificar o distanciamento entre os indivíduos (Betti, 1998).

\section{Há conexões entre formas esportivas estruturalmente distintas e sobrepostas}

Para facilitar o entendimento do processo de transfiguração do mundo esportivo ao longo do tempo, costuma-se separar a análise em dois momentos: um dedicado ao esporte "burguês" e outro ao esporte "de massa". É oportuno examinar esse argumento. O pressuposto desta simplificação analítica é que existem diferentes lógicas ou princípios de estruturação das práticas esportivas. Nesta perspectiva, o estudo do esporte contemporâneo requer que sejam examinados os distintos modelos de organização esportiva (por exemplo: esporte escolar, esporte federado, esporte profissional) e explicitadas as finalidades (divergentes ou não) das práticas e eventos. Dependendo da linha de interpretação, tais modelos e finalidades podem aparecer como elementos sobrepostos, misturados ou ainda em contradição. Ao mesmo tempo, esta perspectiva contribui para que sejam identificadas mais facilmente as transformações nas estruturas sociais e econômicas e na dinâmica cultural, em certas nações, que se refletem visivelmente no mundo esportivo.

Para entender essa sobreposição de formas esportivas estruturalmente distintas, é interessante visitar o pensamento do historiador Fernand Braudel. Um dos principais traços que distingue a obra de Braudel (1995: 12-3) é a definição de três níveis de análise para compreender a história da civilização moderna: o primeiro nível, a base sobre a qual se assentam as trocas, a divisão de trabalho e a sociabilidade, ele denominou de "civilização material"; o segundo nível, o das relações propriamente mercantis, chamou de "economia de mercado"; e o último nível, dos grandes negócios, dos monopólios e das relações econômicas internacionais, achou por bem nomear "capitalismo". Trata-se, segundo ele, de uma "construção dialética", que entende a sociedade e a economia como um todo indivisível, mas cujas estruturas são heterogêneas e complexamente articuladas. Para entender esse todo - diz ele - é prudente começar das estruturas mais simples em direção às mais complexas; e é preciso distinguir os três níveis para poder explicá-los, um em relação ao outro, "no que neles se mistura e no que os opõem”.

Analogamente, é possível examinar a evolução do mundo esportivo em distintos níveis de estruturação, separando as atividades orientadas para o mercado daquelas que não têm finalidade econômica (as práticas educacionais executadas nas escolas e as informais praticadas em clubes, praças e outros espaços públicos). E - mais importante - procurando diferenciar, no conjunto das atividades esportivas mercantilizadas, as que têm sido administradas empresarialmente, tratam os torcedores como 
clientes, cativam um grande público consumidor de espetáculos e preferencialmente se dirigem a mercados internacionais. Partindo de uma visão de conjunto, pode-se privilegiar o esporte-espetáculo enquanto objeto de estudo específico, evitando que se percam de vista suas relações com as demais formas esportivas (o esporte federado, o esporte de academia, o esporte escolar, o esporte informal).

Mas, como pensar na relação entre esses distintos níveis de análise?

Nas sociedades de massa predominantes na era da globalização o caráter civilizador do esporte e a polarização entre amadorismo e profissionalismo foram deslocados para um segundo plano. Possivelmente, se somadas todas as práticas esportivas realizadas durante um ano, a participação relativa de atividades cuja finalidade primordial é o lucro deve ser crescente nas sociedades contemporâneas. Ou melhor, a participação de atividades esportivas voltadas para alguma forma de comercialização tende a se tornar preponderante, em especial nos países com elevada renda per capita. Assim, para entender o mundo esportivo contemporâneo é preciso examinar, em primeiro lugar, como ele está estruturado em função da existência de mercados (entendidos aqui como espaços socioeconômicos onde se encontram, de um lado, uma oferta de certos bens e serviços, e de outro, uma procura por atividades físicas e entretenimento). E é preciso explicar, nos termos de Bourdieu, como se constituem a oferta e a demanda de modalidades, bens e serviços esportivos.

Contudo, a lógica do mercado não explica tudo. Da mesma forma que não existe um significado único associado ao esporte, deve-se recorrentemente lembrar que convivem lado a lado distintas valorações e representações da prática esportiva (e dos vários "consumos" relacionados). Exemplificando: algumas modalidades esportivas contemporâneas, como o golfe, apesar de terem sido espetacularizadas e serem utilizadas em campanhas de publicidade, continuam apresentando um caráter elitizado e uma conotação explícita de distinção social. Segundo Bourdieu (1983: 143):

[...] o esporte ainda traz consigo a marca de suas origens: além da ideologia aristocrática do esporte como atividade desinteressada e gratuita, perpetuada pelos tópicos rituais do discurso de celebração, e que contribui para mascarar a verdade de uma parte crescente das práticas esportivas, a prática de esportes como o tênis, a equitação, o iatismo, o golfe, deve sem dúvida uma parte de seu "interesse", tanto nos dias de hoje quanto em sua origem, aos lucros de distinção que ela proporciona.

Mas, embora as leis do mercado não se apliquem a um vasto conjunto de práticas esportivas já que as motivações originais e as antigas normas de organização permanecem válidas, como ilustram as competições esportivas em escolas, clubes, quartéis e condomínios residenciais -, há conexões estreitas entre os distintos níveis de estruturação. Por exemplo, os colegas de trabalho que participam do torneio de futebol amador, os alunos de educação física que seguem as instruções do professor de basquete, os surfistas que descem no fim-de-semana para o litoral, as moças que treinam natação na 
academia, todos eles são "esportistas" que têm como referência (ou modelo) atletas de ponta dessas modalidades e são potencialmente consumidores de chuteiras, bolas, pranchas, maiôs e outros apetrechos. E, não fossem esses consumidores, o esporte-espetáculo não seria o que é.

Em raros momentos, é possível ver claramente a sobreposição entre as distintas racionalidades presentes na prática esportiva. É o caso de competições em espaços abertos que permitem a participação simultânea de atletas de ponta e de atletas amadores. A Maratona de Nova Iorque e a Corrida de São Silvestre, em São Paulo, são exemplos de eventos nos quais podem estar presentes atletas de diferentes faixas etárias e nacionalidades, com distintos níveis de treinamento e com variadas motivações e expectativas para a corrida; nos quais há atletas profissionais que recebem um cachê para correr, enquanto a imensa maioria dos corredores tem de pagar sua inscrição para participar; nos quais pequenas associações de atletas amadores podem confraternizar e se sentir protagonistas de um evento com alta visibilidade na mídia; nos quais o financiamento vem de patrocinadores e de emissoras de televisão, enquanto o público situado ao longo do percurso pode se divertir e incentivar os participantes sem ter de comprar ingressos; nos quais há grande publicidade de artigos esportivos e são vendidos pacotes turísticos, incluindo consumidores que não são esportistas regulares e não vão participar da prova; nos quais é fundamental a coordenação de ações ou o suporte da prefeitura, que procura conciliar a demanda social por lazer com os ganhos econômicos do turismo para assim legitimar seu calendário anual de eventos esportivos. Além disso, são eventos que despertam o interesse de professores de educação física e estimulam pessoas de todas as classes sociais a correr pelas ruas da cidade onde moram.

Portanto, para entender o esporte-espetáculo é preciso situá-lo no "todo" em que ele se insere, o multifacetado mundo esportivo. Convém começar das estruturas mais simples e caminhar em direção às mais complexas. Em seguida, examinar a evolução do mundo esportivo em seus distintos níveis de estruturação, separando as atividades orientadas para o mercado daquelas que não têm finalidade econômica. O terceiro passo é analisar a diferença entre o consumo de serviços esportivos (como aqueles oferecidos em academias ou escolas de iniciação esportiva) e o consumo de espetáculos (seja ele in loco ou mediado pelos meios de comunicação de massa). Só então é possível apreender como, no caso específico do esporte-espetáculo, a lógica mercantil assume uma dimensão e uma influência muito maiores do que os defensores do profissionalismo poderiam supor em meados do século passado. E só então é aconselhável examinar como as mudanças promovidas no âmbito do esporte-espetáculo afetam as práticas esportivas nas demais esferas de sociabilidade.

\section{As transformações do esporte-espetáculo são mais rápidas e mais profundas}


Finalmente, convém observar os sinais de mudanças no âmbito do esporte, ao longo do século $\mathrm{XX}$, e suas consequências. Entre as várias mudanças ocorridas, destacam-se algumas tendências que contribuíram para a transfiguração do mundo esportivo, a saber: a) a expansão do número de modalidades e de praticantes; b) a crescente diferenciação entre as competições recreativas e as dirigidas ao espetáculo; c) a maior especialização dos treinamentos e a progressiva profissionalização dos atletas; d) a internacionalização dos torneios e a multiplicação de federações esportivas internacionais; e) a transformação do espetáculo esportivo em fonte de receitas para empresas de comunicação de massa; f) o desenvolvimento do marketing esportivo e a completa mercantilização do esporte-espetáculo; g) a disputa crescente entre governos para sediar grandes eventos esportivos em virtude de seus potenciais legados.

Pode-se dizer que o mundo esportivo passou por mudanças quantitativas e qualitativas, que expandiram seu campo de ação, seu valor social e seus significados. Houve um crescimento "horizontal" do conjunto de elementos abarcados pelo esporte, com a diversificação de modalidades e a difusão das práticas entre as classes sociais e para diferentes regiões do planeta. Simultaneamente, houve um crescimento "vertical", com a espetacularização dos torneios, o surgimento de divisões e a proliferação de federações nacionais e internacionais, o que conformou uma hierarquia técnica e uma concentração de poder político no interior daquele conjunto. Além disso, houve um crescimento exponencial dos valores de contratos de patrocínios e de direitos de transmissão, assim como dos pagamentos aos atletas e dos custos operacionais, o que exigiu a adoção de modelos de gestão empresarial nos clubes e ligas esportivas.

Estas tendências ampliaram as distâncias entre as práticas esportivas motivadas pela intenção dos praticantes (o esporte como lazer, ainda que institucionalizado) e as competições esportivas destinadas a um público pagante (o esporte-espetáculo). Não só porque há um grande desnível em termos de grau de habilidade, condicionamento físico e infraestrutura, mas porque estão em jogo interesses e recompensas totalmente diferentes. Os próprios desdobramentos econômicos, sociais e políticos delimitam um distanciamento insuperável entre esses tipos de atividade esportiva.

Nesse sentido, é bom notar que as transformações que ocorrem no âmbito do esporteespetáculo são muito mais profundas - e se dão num ritmo mais acelerado - do que as que afetam a maior parte do universo esportivo. Um bom exemplo para entender essa afirmação é dado pelos Jogos Olímpicos. Quando as primeiras edições das Olimpíadas ainda reuniam algumas centenas de esportistas amadores, não havia muita distância em relação à forma como as competições eram disputadas em clubes sociais ou em universidades, nem em relação à sua finalidade. Com o passar do tempo, o termo "amadorismo" tornou-se cada vez mais incongruente com o vocabulário olímpico. Atualmente é despropositado comparar o desempenho, a organização e a repercussão de um torneio amador 
disputado num clube social ou numa universidade com as badaladas competições olímpicas. A exceção que confirma a regra é o esporte universitário norte-americano, no qual os atletas permanecem amadores, mas técnicos e dirigentes são profissionais e os campeonatos se transformaram em espetáculos para o grande público televisivo.

Outro ponto importante a destacar é que a concorrência mais acirrada no âmbito do esporteespetáculo induz uma busca incessante por inovações, seja para aumentar o rendimento dos atletas e as chances de vitória das equipes, seja para valorizar o espetáculo, ampliar os mercados e elevar as receitas. O poder econômico tende a se refletir sobre o desempenho esportivo e a aumentar a distância entre o esporte-espetáculo e as demais formas esportivas, uma vez que poucos podem comprar bicicletas iguais às usadas no Tour de France, treinar em pistas de atletismo com piso sintético, ou filmar os movimentos embaixo d'água para melhorar sua eficiência. Mas, ainda que as inovações tecnológicas adotadas no âmbito do esporte-espetáculo não sejam imediatamente acessíveis aos demais praticantes de uma modalidade esportiva, muitas acabam sendo, lentamente, difundidas.

As mudanças nas regras e as novas formas de disputa introduzidas nos torneios transmitidos pela televisão acabam tendo influência sobre os hábitos e comportamentos esportivos de todos os tipos de praticante. É o caso, por exemplo, do voleibol, que alterou o sistema de pontuação para tornar a disputa mais emocionante e diminuir o tempo de duração da partida. A nova regra foi imediatamente incorporada nas escolas, nas praias, nas quadras destinadas ao "esporte para todos". Nesse sentido, pode-se dizer que o público, em geral, procura praticar uma modalidade seguindo as mesmas condições impostas aos atletas de ponta, aos ídolos nos quais se espelham.

Mas, isso não significa que a prática esportiva não institucionalizada seja meramente um reflexo da prática exaltada pela mídia. Por exemplo, a regra do líbero (também no voleibol) não costuma ser adotada entre praticantes de fim-de-semana, uma vez que estes podem recusar a regra que impede um jogador de atuar junto à rede e de atacar. O mesmo vale para a regra do impedimento (no futebol), que exige a presença de um "bandeirinha" e é sempre objeto de discussão, o que leva muitos "boleiros" de fim-de-semana a descartar essa regra. De fato, muitas maneiras tradicionais de praticar uma modalidade têm sido intencionalmente preservadas e regras têm sido flexibilizadas (p.e., a regra de substituição de jogadores), procurando assegurar que a competição esportiva permita a participação do maior número possível de pessoas. Em outras palavras, os próprios praticantes amadores têm consciência das diferenças que separam o esporte praticado na escola ou no clube do chamado "esporte-espetáculo".

Em suma, são as mudanças promovidas no âmbito do esporte-espetáculo que proporcionam maior dinamismo ao mundo esportivo, indicando os rumos ou tendências predominantes e induzindo transformações na maneira como as modalidades esportivas são praticadas nos demais âmbitos. Mas, também é preciso considerar que há inércia e resistência, que há espaços de autonomia e criatividade. E 
que o esporte-espetáculo provavelmente encontraria muitas dificuldades para se renovar, se esses espaços de autonomia e criatividade fossem completamente eliminados.

\section{Considerações finais}

Este artigo pretendeu contribuir para o debate que vem sendo travado na América Latina, onde se verifica uma pluralidade de estudos que procuram retratar realidades às vezes similares, às vezes díspares, presentes no mundo esportivo. As proposições feitas ao longo do texto procuraram sugerir que uma postura metodológica flexível e uma matriz teórica eclética e coerente podem trazer um avanço significativo neste terreno acadêmico.

Por ser um termo "polissêmico", muitos especialistas consideram que o esporte deve ter uma definição ampla, flexível e inclusiva. Deve-se reconhecer que se tornou cada vez mais difícil definir o que é o esporte, seja do ponto de vista antropológico-cultural, seja da perspectiva das relações e estruturas sociais que nele se manifestam. "Esporte" é um termo cujo significado, além de modificar-se, segue ampliando-se, tanto ao se referir a atividades e atitudes humanas como, sobretudo, ao englobar um conjunto de situações e instituições sociais submetidas a frequentes mudanças. Analogamente, pode-se dizer que os caminhos para estudar o esporte são muitos e que há muito a ganhar com a diversidade de enfoques e a formação de grupos de pesquisa reunindo especialistas de diversas disciplinas.

Tanto historiadores quanto sociólogos, quando se dedicam a entender as relações sociais presentes no esporte contemporâneo, se deparam com forças de transformação e de conservação que permanentemente atuam sobre o mundo esportivo. Embora o objetivo de uma reflexão sociológica possa ser muito diferente do propósito de uma investigação histórica, tem aumentado o número de iniciativas que pretendem conciliar as duas abordagens, o que torna fundamental buscar diálogos com diferentes vertentes teóricas para vencer o desafio de realizar uma análise interdisciplinar.

Uma das dificuldades para pesquisas interdisciplinares é encontrar um meio-termo entre as teorias gerais, que procuram encaixar a realidade dentro de modelos abstratos e perdem assim a riqueza do processo histórico, de um lado, e as narrativas particulares, que se fixam nas especificidades e acabam confinadas a estudos de caso, de outro. Para isso, é preciso descartar os conceitos rígidos, evitar vestir uma camisa-de-força conceitual, sem que isso implique deixar de recorrer a modelos interpretativos ou negar a utilização de categorias de análise. Na verdade, esta postura exige que cada grupo de pesquisa construa um quadro conceitual adequado ao seu objeto e se responsabilize por compatibilizar distintas linhas explicativas.

Para finalizar, é importante esclarecer que as proposições apresentadas não têm interesse meramente acadêmico. Ou melhor, é preciso lembrar que o debate acadêmico pode ter implicações 
sociopolíticas e que a reflexão proposta no artigo pode contribuir para a discussão de linhas de ação, seja no campo da educação física, seja no âmbito da política de esporte. Neste sentido, é necessário ressaltar o papel das políticas públicas nessa área: na regulamentação da prática esportiva, na oferta de espaços apropriados para a população em geral, na definição de diretrizes educacionais, no estímulo ao esporte de alto rendimento, na veiculação de discursos sobre o que é recomendável e legítimo. Assim, é muito importante frisar que as ações e programas do Estado (em todos os níveis de governos) têm ajudado a estruturar e ampliar o campo de influência das instituições esportivas, têm fortalecido determinados segmentos e interesses em detrimento de outros, assim como têm contribuído para soldar certos vínculos entre práticas e consumos no mundo esportivo.

\section{Referências}

ALABARCES, P. (org.) (2003). Futbologías: fútbol, identidad y violencia en América Latina. Buenos Aires: Clacso.

BAUMAN, Z. (2001). Modernidade líquida. Rio de Janeiro: Jorge Zahar.

BETTI, M. (1998). A janela de vidro: esporte, televisão e educação física. Campinas: Papirus.

BOURDIEU, P. (1983). Como é possível ser esportivo? In: Questões de sociologia. Rio de Janeiro: Marco Zero.

BRACHT, V. (1997). Sociologia crítica do esporte: uma introdução. Vitória: UFES.

BRAUDEL, F. (1995). Civilização material, economia e capitalismo. São Paulo: Martins Fontes, vol. 1.

BROHM, J. M. (1982). Sociología política del deporte. Ciudad del México: Fondo de Cultura Económica.

CAGIGAL, J. M. (1979). Cultura intelectual e cultura física. Buenos Aires: Kapelusz.

CARDOSO DE MELLO, J. M. \& NOVAIS, F. (2009). Capitalismo tardio e sociabilidade moderna. São Paulo: Editora da Unesp; Campinas: Facamp.

CORNEJO A., M.; MARCHI JÚNIOR, W. (Org.) (2008). Estudios y proyectos en sociología del deporte y la recreación en América Latina. Concepción: Asociación Latinoamericana de Estudios Socioculturales del Deporte - ALESDE.

ELIAS, N. \& DUNNING, E. (1995). Deporte y ocio en el proceso de la civilización. México: Fondo de Cultura Económica.

GARCIA FERRANDO, M. (1990). Aspectos sociales del deporte: una reflexión sociológica. Madrid: Alianza Editorial. 
GEBARA, A. (1995). Esportes: cem anos de história. in: Coletânea do III ENCONTRO NACIONAL DE HISTÓRIA DO ESPORTE, LAZER E EDUCAÇÃO FÍSICA, Curitiba, UFPR.

GUTTMANN, A. (1978). From ritual to record: the nature of modern sports. New York: Columbia University Press.

HELAL, R. (1990). O que é sociologia do esporte. São Paulo: Brasiliense.

HOBSBAWM, E. J. (1995). Era dos extremos, o breve século XX: 1914-1991. São Paulo: Companhia das Letras.

HOLT, R. (1989). Sport and the British: a modern history. Oxford: Claredon Press.

KELLNER, D. (1996). Sports, media culture and race - some reflections on Michael Jordan, Sociology of Sport Journal, v. 13, n. 4.

LASCH, C. (1986). O mínimo eu - sobrevivência psíquica em tempos difíceis. São Paulo: Brasiliense.

LUCENA, R. (2001). O esporte na cidade: aspectos do esforço civilizador brasileiro. Campinas: Autores Associados.

LÜSCHEN, G.; WEIS, K. (org.) (1979). Sociologia del deporte. Valladolid: Miñón.

MANDELL, R. (1984). Sport: a cultural history. New York: Columbia University Press.

MARCHI JÚNIOR, W. (2004). “Sacando” o voleibol. São Paulo: Hucitec; Ijuí: Ed. Unijuí.

McPHERSON, B. D.; CURTIS, J. E.; LOY, J. (1989). The social significance of sport: an introduction to the sociology of sport. Campaign: Human Kinetics Books.

POCIELLO, C. (1984). Sport e société: approche socio-culturelle des pratiques. Paris: Vigot.

PRONI, M. W. (1998). Esporte-espetáculo e futebol-empresa. Tese de Doutorado em Educação Física. Campinas, Unicamp.

PRONI, M. W.; LUCENA, R. (org.) (2003). Esporte: história e sociedade. Campinas: Autores Associados.

RIBEIRO, L. C. (org.) (2007). Futebol e globalização. Jundiaí-SP: Fontoura.

TUBINO, M. J. G. (1997). Teoria geral do esporte. São Paulo: Ibrasa.

VAZ, A. F. (2007). Teoria crítica do esporte: origens, polêmicas, atualidade. Esporte e Sociedade, ano 3, n. 7, nov.2007-fev.2008.

VILLENA, S. (2003). El fútbol y las identidades. Prólogo a los estudios latinoamericanos. In: ALABARCES, P. (org.) Futbologías: fútbol, identidad y violencia en América Latina. Buenos Aires: Clacso. 